\title{
PENGARUH BERBAGAI MACAM PACKING KOLOM TERHADAP KUALITAS AIR KEBUTUHAN BOILER (STUDI KASUS PADA ALAT ION EXCHANGER SISTEM BATCH DAN KONTINYU)
}

\author{
Zulriadi dan Prayogo Danardono \\ Jurusan Teknik Kima, Politeknik Negeri Malang \\ (Artikel diterima: Oktober 2019, direvisi: September 2019, diterima untuk terbit: Januari 2020)
}

\begin{abstract}
Abstrak - Pertukaran ion dapat berlangsung antara dua elektrolit atau antara suatu larutan elektrolit dengan sebuah komplek. Biasanya istilah ini mengacu kepada proses pemurnian, pemisahan, dan dekontaminasi larutan dengan penukar ion padat yang bersifat polimerik atau mineralik. Benda yang $b$ iasa digunakann untuk melakukan pertukaran ion adalah resin penukar ion, zeolit, karbon aktif, tanah liat, dan humus tanah. Pertukaran ion merupakan reaksi dua arah dan penukar ion dapat diregenerasi atau dimuat dengan ion yang dinginkan dengan cara membasuhnya dengan kelebihan ion tersebut. Pertukaran ion melibatkan butiran butiran resin dengan permukaan yang bermuatan positif (kation) dan negatif (anion). Biasanya resin -resin tersebut memiliki pori - pori kecil untuk menambah luas permukaan kontak. Lama waktu kontak juga mempengaruhi dari hasil dari kesadahan air yang diperoleh. Maka dari itu perlu dicari waktu optimum isian kolom untuk kontak dengan air yang dimurnikan.
\end{abstract}

Kata kunci: Ion Exchanger, Isian kolom packing.

\section{Pendahuluan}

Kebutuhan akan air mutlak diperlukan baik yang mengandung mineral maupun yang tidak mengandung mineral (pure water). Untuk kebutuhan mahkluk hidup air mineral sangat diperlukan untuk dikomsumsi, sedangkan untukkeperluan proses di industri khususnya industri kimia justru sebaliknya. Pengaruh mineral pada proses industri kimia cukup komplek yaitu dari memyebabkan kerak pada proses pemanasan seperti boiler dan heat exchanger,sampai turunnya yield dan selektivitas pada proses reaksi, dan masih banyak lagi pengaruhlainnya. Untuk itu diperlukan suatu unit pengolahan air untuk menghilangkan kandunganmineral sebelum air tersebut digunakan dalam suatu industri khususnya industri kimia.

Berdasarkan latar belakang tersebut, maka permasalahan yang akan dipecahkan dalam penelitian ini dirumuskan sebagai berikut:

1. Manakah isian yang paling optimum pada paking kolom isian dengan waktu kontak yang sama pada alat ion exchange untuk proses batch dan proses kontinyu.

2. Bagaimana mendapatkan kondisi optimum pada peralatan ion exchange berikut:

Batasan masalah pada penelitian ini adalah sebagai

1. Penentuan bahan untuk variabel menggunakan resin kation, anion, dan karbon aktif

2. Jenis pengendali yang digunakan adalah lama waktu kontak yang sama tiap packing kolom

Tujuan dari penelitian ini adalah:

1. Mengentahui pengaruh isian packing kolom ion exchange pada pengolahan air kebutuhan boiler dengan waktu kontak yang sama.

2. Mengetahui isian packing kolom ion exchanger yang paling optimum pada pengolahan air kebutuhan boiler

\section{KaJian PUSTAKa}

\section{A. Ion Exchanger}

Ion exchanger atau resin penukar ion dapat didefinisikan sebagai senyawa hidrokarbon terpolierisasi yang mengandung ikatan silang (crosslinking) serta gugus-gugus fungsional yang mempunyai ion-ion yang dapat dipertukarkan. Sebagai zat penukar ion resin mempunyai karakteristik yang berguna dalam analisis kimia, antara lain kemampuan menggelembung (selling), kapasitas penukuran dan selektivitas penukaran. Pada saat dikontakkan dengan resin penukar ion, maka ion terlarut dalam air akan terserap ke resin penukar ion dan resin akan melepaskan ion lain dalam kesetaraan ekivalen, dengan melihat kondisi tersebut maka dapat mengatur jenis ion yang diikat dan dilepas.

Sebagai media penukar ion, maka resin penukar ion harus memenuhi syarat-syarat sebagai berikut :

- Kelarutan yang rendah dalam berbagai larutan sehingga dapat digunakan berulang-ulang. Resin akan bekerja dalam cairan yang mempunyai sifat melarutkan, karena itu harus tahan terhadap air.

- Kapasitas yang tinggi, yaitu resin memiliki kapasitas pertukaran ion yang tinggi.

- Kestabilan fisik yang tinggi, yaitu resin diharapkan tahan terhadap tekanan mekanis tekanan hidrostatis cairan serta tekanan osmosis. (Sumber : Anonim, 2014)

\section{B. Prinsip Pertukaran Ion}

Ion Penukar ion kebanyakan berupa bahan bahan organik, yang umumnya dibuat secara sintetik. Bahan tersebut sering juga disebut resin penukar ion. Penukar ion mengandung bagian-bagian aktif dengan ion yang dapat ditukar Bagian aktif semacam itu misalnya adalah:

- Pada penukar kation: Kelompok-kelompok asam sulfo $\mathrm{SO} 3-\mathrm{H}+$ (dengan sebuah ion $\mathrm{H}+$ yang dapat ditukar) Pada penukar anion: Kelompok-kelompok amonium kuartener - N- (CH3)3 + OH- (dengan sebuah ion OHyang dapat ditukar) Pertukaran ion adalah proses 
fisika-kimia.

Pada proses tersebut senyawa yang tidak larut, dalam hal ini resin menerima ion positif atau negatif tertentu dari larutan dan melepaskan ion lain kedalam larutan tersebut dalam jumlah ekivalen yang sama. Jika ion yang dipertukarkan berupa kation, maka resin tersebut dinamakan resin penukar kation, dan jika ion yang dipertukarkan berupa anion, makan resin tersebut dnamakan resin penukar anion.

Contoh reaksi pertukaran kation dan reaksi pertukaran anion disajikan pada reaksi :

Reaksi pertukaran kation:

$2 \mathrm{NaR}(\mathrm{s})+\mathrm{CaCl} 2$ (aq) $\longrightarrow \mathrm{CaR}(\mathrm{s})+2 \mathrm{NaCl}$ (aq)

Reaksi pertukaran anion :

$2 \mathrm{RCl}(\mathrm{s})+\mathrm{Na} 2 \mathrm{SO} 4 \longrightarrow \mathrm{R} 2 \mathrm{SO} 4(\mathrm{~s})+2 \mathrm{NaCl}$

Reaksi pertukaran kation menyatakan bahwa larutan yang mengandung $\mathrm{CaCl} 2$ diolah dengan resin penukar kation $\mathrm{NaR}$, dengan $\mathrm{R}$ menyatakan resin. Proses penukaran kation yang diikuti dengan penukaran anion untuk mendapatkan air yang bebas dari ion-ion penyebab kesadahan. Konstanta disosiasi air sangat kecil dan reaksi dari $\mathrm{H}+$ dengan OHsangat cepat. Ketika semua posisi pertukaran yang awalnya dipegang $\mathrm{H}+$ atau ion OHyang menempati $\mathrm{Na}+$ atau $\mathrm{Cl}-$ (kation atau anion lain) yang masing-masing resin dikatakan habis. Resin kemudian dapat diregenerasi dengan ekuilibrasi menggunakan asam atau basa yang sesuai.

(Sumber : Anonim, 2015)

\section{Kesadahan Air}

Tingkat kesadahan di berbagai tempat perairan berbedabeda, pada umumnya air tanah mempunyai tingkat kesadahan yang tinggi, hal ini terjadi, karena air tanah mengalami kontak dengan batuan kapur yang ada pada lapisan tanah yang dilalui air. Air permukaan tingkat kesadahan-nya rendah (air lunak), kesadahan non karbonat dalam air permukaan bersumber dari calsium sulfat yang terdapat dalam tanah liat dan endapan lainnya. Tingkat kesadahan air biasanya digolongkan seperti ditunjukkan pada tabel berikut ini.

Tabel 1. Tingkat Kesadahan Air

\begin{tabular}{|l|l|}
\hline $\mathrm{Mg} / \mathrm{l} \mathrm{CaCO} 3$ & Tingkat Kesadahan \\
\hline $0-75$ & Lunak (soft) \\
\hline $75-150$ & Sedang (moderately hard) \\
\hline $150-300$ & Tinggi (hard) \\
\hline$>300$ & Tinggi sekali (very hard) \\
\hline
\end{tabular}

(Sumber : Anonim, 2013)

Tingkat kesadahan air dapat dinyatakan dalam satuan $\mathrm{mg} / \mathrm{L} \mathrm{CaCO} 3$ atau ppm $\mathrm{CaCO} 3$ atau dalam satuan Grain atau derajat. Hubungan antara satuan-satuan tersebut adalah sebagai berikut :

$\begin{aligned} 1 \text { grain per US gallon } & =1^{\circ} \text { (derajat) } \\ & =17,1 \mathrm{ppm} \mathrm{CaCO} 3 \\ 100 \mathrm{ppm} \mathrm{CaCO} 3 & =40 \mathrm{ppm} \mathrm{kalsium} \\ 1 \text { derajat (Inggris) } & =10 \mathrm{mg} \mathrm{CaCO} / 0,7 \mathrm{~L} \text { air } \\ & =14,3 \mathrm{mg} \mathrm{CaCO} 3 / 1 \text { air } \\ 1 \text { derajat (Jerman) } & =10 \mathrm{mg} \mathrm{CaCO} 3 \\ & =17,8 \mathrm{mg} \mathrm{CaCO} 3 / 1 \text { air } \\ 1 \text { derajat (perancis ) } & =10 \mathrm{mg} \mathrm{CaCO} 3 / 1 \text { air }\end{aligned}$

1 derajat (perancis) $\quad=10 \mathrm{mg} \mathrm{CaCO} 3 / 1$ air

\section{Karbon Aktif}

Karbon aktif adalah senyawa karbon yang telah ditingkatkan daya adsorpsinya dengan melakukan proses karbonisasi dan aktivasi. Pada proses tersebut terjadi penghilangan hidrogen, gas-gas dan air dari permukaan karbon sehingga terjadi perubahan fisik pada permukaannya. Aktivasi ini terjadi karena terbentuknya gugus aktif akibat adanya interaksi radikal bebas pada permukaan karbon dengan atomatom seperti oksigen dan nitrogen. Karbon aktif terdiri dari 87 - $97 \%$ karbon dan sisanya berupa hidrogen, oksigen, sulfur dan nitrogen serta senyawa-senyawa lain yang terbentuk dari proses pembuatan. Volume pori-pori karbon aktif biasanya lebih besar dari $0,2 \mathrm{~cm} 3$ /gram. Pada dasarnya karbon aktif dapat dibuat dari semua bahan yang mengandung karbon baik yang berasal dari tumbuhtumbuhan, binatang maupun barang tambang seperti berbagai jenis kayu, sekam padi, tulang binatang, batu bara, kulit biji kopi, tempurung kelapa, tempurung kelapa sawit dan lain-lain Bahan-bahan alami tersebut dipreparasi dengan cara karbonisasi dan aktivasi sehingga menghasilkan karbon aktif. Karbon aktif digunakan pada berbagai bidang aplikasi sesuai dengan jenisnya. (Anonim, 2015)

\section{E. Jenis-jenis Resin Penukar Ion}

Berdasarkan jenis gugus fungsi yang digunakan, resin penukar ion dapat dibedakan menjadi empat jenis yaitu :

1. Resin penukar kation asam kuat (mengandung gugusan HSO3) Contoh paling baik dari resin penukar kation asam kuat adalah "principal sulfonated styrene-divinylbenzene copolymer produc" seperti amberlite IRP69 (Rhom dan Haas) dan DOWEX MSC-1 (Dow Chimical). Resin ini dapat digunakan untuk menutup rasa dan aroma zat aktif kationik (mengandung amin) sebelum diformulasi dalam tablet kunyah. Resin ini merupakan produk sferik yang dibuat dengan mensulfonasi butir-butir kopolimer divinilbenzen srien dengan zat pensulfonasi pilihan berupa asam sulfat, asam klorosulfonoat, atau sulfur trioksida. Penggunaan zat pengembang yag non reaktif umumnya diperlukan untuk pengembangan yang cepat dan seragam dengan kerusakan minimum. Resin penukar kation asam kuat berfungsi diseluruh kisaran $\mathrm{pH}$.

2. Resin penukar kation asam lemah (mengandung gugusan $\mathrm{COOH})$ Resin penukar kation asam lemah yang paling umum adalah yang dibuat dengan tautan silang atau asam karboksilat tak jenuh seperti asam metakrilat dengan suatu zat tautan silang seperti divinilbenzen. Contohnya mencakup DOWEX CCR-2 (DOW chemical) dan Amberlit IRP-65 (Rhom dan Haas). Resin pertukaran kation asam lemahberfungsi pada $\mathrm{pH}$ diatas 6 .

3. Resin penukar anion basa kuat (mengandung gugusan amina tersier atau kuartener) Resin penukar anion basa kuat adalah resin amin kuartener sebagai hasil dari reaksi trietilamin yang kopolimer dari stiren dan dvinil benzen yang diklorometilasi, misalnya amberlite IRP-276 (Rhom and Hass), dan DOWEX MSA-A (DOWnChemical). Resin penukar anion basa kuat ini befungsi diseluruh kisaran $\mathrm{pH}$.

4. Resin penukar anion basa lemah ( mengandung $\mathrm{OH}$ sebagai gugusan labil). Resin penukar ion basa lemah 
dibentuk dengan mereaksikan amin primer dan amin sekunder atau amonia dengan kopolimer stiren dan divinil benzene yang diklorometilasi, biasanya digunakan dimetilamin. Resin penukar anion basa lemah ini berfungsi dengan baik dibawah $\mathrm{pH}$. (Sumber : Imansyahrul, 2014)

\section{BAHAN DAN METODE}

A. Alat dan Bahan

Alat

- Seperangkat alat ion exchanger

Beaker glass plastik $1000 \mathrm{~mL}$

- Beaker glass $600 \mathrm{ml} \quad$ - $\quad$ Batang pengaduk

- Stop watch _ - Gelas ukur $100 \mathrm{~mL}$

- Buret

- Labu ukur

- $\quad$ Pipet tetes

- Corong gelas

\section{Bahan}

- Air sample

- Resin kation

- Resin anion

- Karbon Aktif

- Larutan

Na2EDTA.2H2O

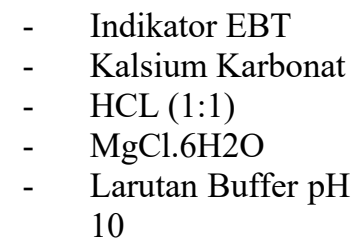

B. Prosedur dan Skema Kerja

\section{Prosedur Kerja}

\section{Persiapan isian kolom packing}

- Mengisis kolom isian dengan bahan yang akan diteliti secara bergantian ( resin kation, resin anion, dan karbob aktif)

- Mempersiapkan air sample untuk diolah kesadahannya

2. Melaksanakan proses ion exchange pada alat ion exchanger

- Menjalankan proses ion exchanger dengan sistem batch

- Mengatur waktu kontak masing - masing bahan isian kolom packing

- Mengambil data hasil pengolahan dan dilakukan analisa kesadahan air

\section{Skema Kerja}

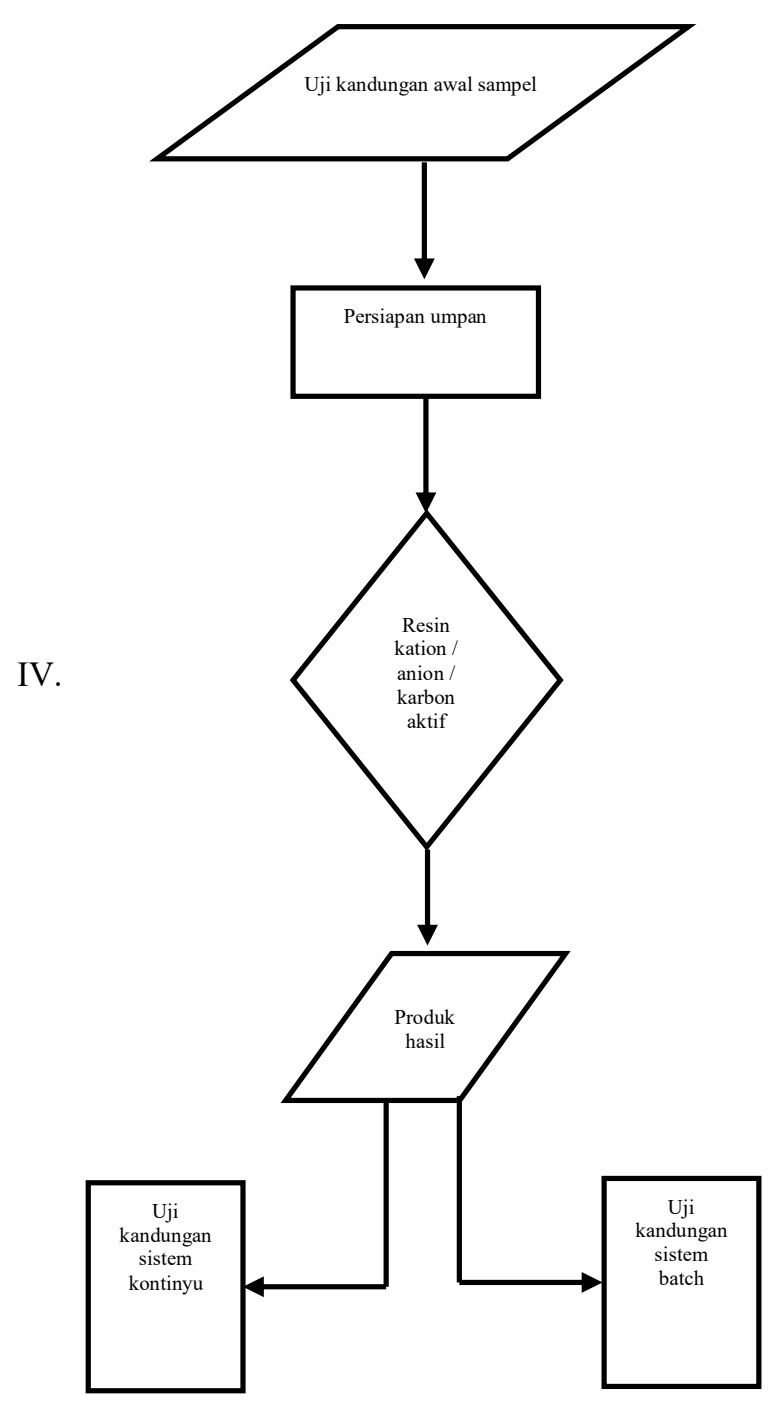

\section{Hasil Dan Pembahasan}

\section{A. Data Analisa}

\begin{tabular}{|c|c|c|c|c|}
\multicolumn{5}{|c|}{ Tabel 1. Sistem Batch volum air sample $500 \mathrm{ml}$} \\
\hline \multirow{2}{*}{$\begin{array}{c}\text { WAKT } \\
\text { U } \\
(\text { MENI } \\
\text { T) }\end{array}$} & $\begin{array}{c}\text { KARBON } \\
\text { AKTIF }\end{array}$ & ANION & KATION & GABUNGAN \\
\cline { 2 - 5 } & 342.37 & 341.33 & 340.01 & 321.06 \\
\hline 5 & 335.28 & 325.22 & 325.05 & 264.39 \\
\hline 10 & 348.88 & 340.15 & 322.25 & 210.02 \\
\hline 15 & 344.21 & 331.1 & 338.01 & 188.24 \\
\hline 20 & 351.01 & 308.65 & 255.62 & 160.92 \\
\hline 25 & 344.25 & 255.51 & 220.97 & 142.51 \\
\hline 30 & 318.02 & 262.11 & 131.26 & 110.29 \\
\hline 35 & 320.22 & 241.31 & 108.05 & 79.64 \\
\hline 40 & & & & \\
\hline
\end{tabular}




\begin{tabular}{|l|l|l|l|l|}
45 & 324.28 & 218.28 & 88.52 & 60.58 \\
\hline 50 & 331.59 & 221.02 & 36.23 & 44.21 \\
\hline
\end{tabular}

Tabel 2. Sistem kontinue dengan laju alir air sample $1 \mathrm{ml} / \mathrm{s}$

\begin{tabular}{|c|c|c|c|c|}
\hline \multirow{2}{*}{ WAKTU } & \multicolumn{4}{|c|}{ KESADAHAN AIR (ppm) } \\
\cline { 2 - 5 } & $\begin{array}{c}\text { KARBON } \\
\text { AKTIF }\end{array}$ & ANION & KATION & GABUNGAN \\
\hline 5 & 344.13 & 336.1 & 302.01 & 325.06 \\
\hline 10 & 342.12 & 320.31 & 277.05 & 244.39 \\
\hline 15 & 344.88 & 308.11 & 219.25 & 230.02 \\
\hline 20 & 320.15 & 311.2 & 152.01 & 198.24 \\
\hline 25 & 338.18 & 254.27 & 155.62 & 156.92 \\
\hline 30 & 341.25 & 209.18 & 120.18 & 140.51 \\
\hline 35 & 322.97 & 221.13 & 111.28 & 108.29 \\
\hline 40 & 338.2 & 211.01 & 104.02 & 78.64 \\
\hline 45 & 329.53 & 226.34 & 68.17 & 57.58 \\
\hline 50 & 335.07 & 220.08 & 40.43 & 41.21 \\
\hline
\end{tabular}

\section{B. Grafik Hasil Data Pengamatan}

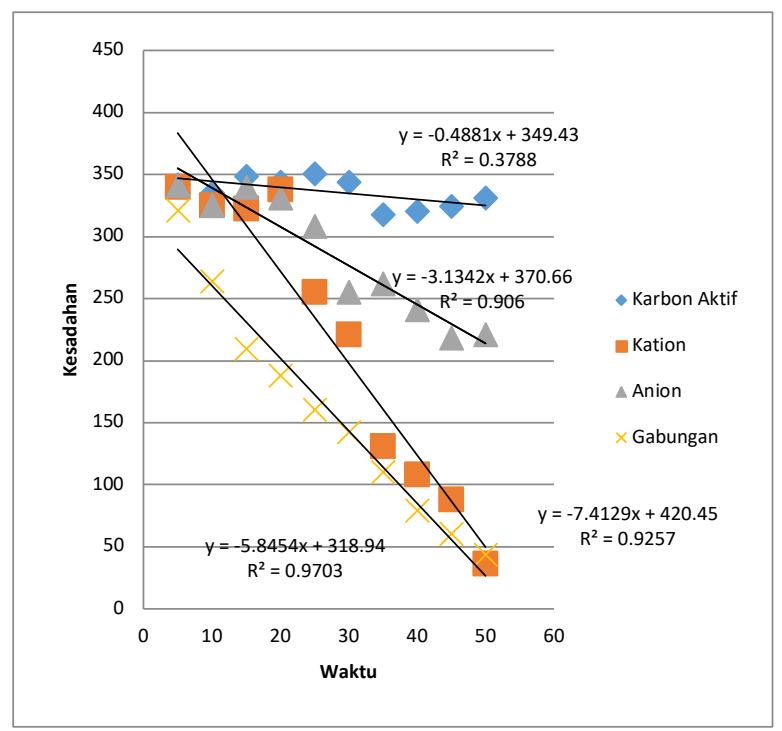

Gambar 1. Sistem Batch volum air sample $500 \mathrm{ml}$

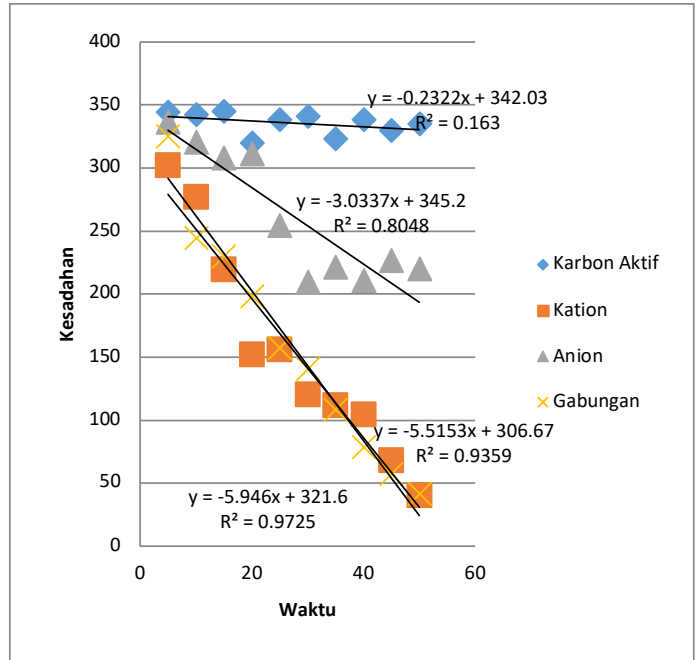

Gambar 2. Sistem kontinue dengan laju alir air sample $1 \mathrm{ml} / \mathrm{s}$

\section{Pembahasan}

Dari hasil penelitian yang dilakukan dengan menggunakan berbagai jenis isian kolom packing telah didapatkan berbagai data seperti diatas. Dari data diatas dapat diliat bahwa untuk isian karbon aktif baik dalam system batch maupun continue tidak memberikan pegaruh yang terlalu besar, dilihat dari grafik yang didapat menunjukkan hasil yang mendatar dari nilai awal $342,37 \mathrm{ppm}$ setelah 50 menit menjadi 331,59 ppm. Berbeda dengan isian kation dan anion kedua isian packing kolom ini dapat memberikan perubahan dari nilai kesadahan air yang diproses untuk isian anion nilai kesadahan awal sebesar 341,33 ppm menjadi 221,02 ppm, tetapi diantara keduanya yang memberikan perubahan yang paling signifikan adalah untuk isian kolom kation yang bisa menurunkan kesadahan yang hampir setengah dari kesahan air tiap waktunya dari niali kesadahan awal 340,01 ppm setelah melalui proses selama 50 menit menjadi $36,23 \mathrm{ppm}$. Untuk hasil analisa yang paling bagus adalah hasil dengan menggabungkan kesemua bahan isian packing kolom. Kesadahan yang dihasilkan bisa turun lebih dari setengah kesadahan air awal yaitu $321,06 \mathrm{ppm}$ setelah diproses selama 50 menit menjadi $44,21 \mathrm{ppm}$.

Untuk perlakuan proses secara continue hasil yang didapatkan tidak jauh beda dengan yang system batch namun untuk yang continue hasil yang diperoleh lebih bagus dibandingkan dengan bacth karena air diproses secara mengalir.kecuali karbon aktif yang kurang memberikan pengaruh terhadap nilai kesadahan air terlihat dari nilai kesadahan awal 344,13 ppm setelah diproses selama 50 menit nilai kesadahannya menjadi $335,07 \mathrm{ppm}$. Untuk nilai kesadahan hasil proses dengan menggunakan anion menurun dari 336,1 ppm menjadi 220,07 ppm. Dan untuk isian kation tetap menghasilkan penururan kesadahan yang paling baik diantara keduanya yaitu dari nilai kesadahan awal 302,01 ppm menjadi 40,43 ppm. Hasil untuk isian gabungan juga hasilnya lebih bagus dibandingkan dengan system batch yaitu dari nilai kesadahan awal sebesar 325,06 setelah diproses selama 50 menit turun menjadi $41,21 \mathrm{ppm}$. System kontinue ini menguntungkan apabila dilakukan dalam industry sehingga air tidak harus ditampung terlebih dahulu dalam wadah tertentu dahulu sebelum proses, tetapi bisa langsung dialirkan menuju system proses selanjutnya. 


\section{KeSIMPULAN}

Berdasarkan dari pembahasan diatas dapat disimpulkan bahwa :

1. Isian kolom packing mempengaruhi hasil dari kesadahan air yang diproses. Isian kation lebih bagus dibandingkan dengan anion, dan isian karbon aktif kurang memberikan pengaruh pada proses ionexcahange sehingga kurang memberikan pengaruh hasil penurunan kesadahan air yang diproses.

2. Untuk system batch dan system continue juga menghasilkan perubahan yang berbeda. System continue lebih baikdibandingkan dengan system batch. Semakin lama waktu kontak maka akan semakin turun kesadahan air yang di proses.

3. Perubahan kesadahan air menggunakan karbon aktif awal 344,13 ppm setelah diproses selama 50 menit nilai kesadahannya menjadi 335,07 ppm.. Isian anion menurun dari 336,1 ppm menjadi 220,07 ppm. nilai kesadahan awal kation juga menurun dari kesadahan awal 302,01 ppm menjadi 40,43 ppm. Namun apabila ketiga isian digabung maka hasil proses ion exchangernya lebih maksimal untuk proses continue karena bisa menurunkan kesadahan dari kesadahan awal 325,06 setelah diproses selama 50 menit turun menjadi $41,21 \mathrm{ppm}$.

\section{DAFTAR PUSTAKA}

[1] Coulson, JM \& JF Richardson. 2002. Chemical Engineering.Volume 2.Fifth Edition. Particle Technology and Separation Processes. Bath : TheBath Press

[2] Geankoplis, Christie J. Transport Processes and Unit Operation.Second Edition. Allyn and Bacon

[3] Kister, Henry Z.1990. ion exchanger. New York :McGraw Hill Inc

[4] Woolf, Peter J. 2006. Chemical Process Dynamics \& Control. Open textbook. Michigan :University of Michigan 